\title{
AEC \\ CORRELATION OF RADIATION DAMAGE IN BORONATED GRAPHITE
}

RESEARCH

BNWL-199

$33-$

\section{and}

DEVELOPMENT

REPORT

\author{
R. E. DAHL
}

FEBRUARY, 1966
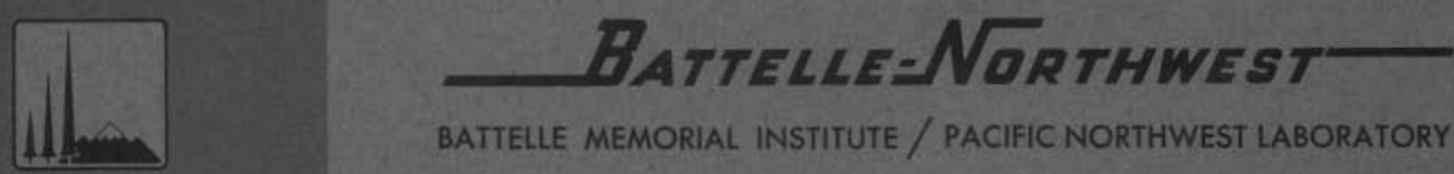

BATTELLE MEMORIAL. INSTITUTE / PACIFIC NORTHWEST LABORATORY 


\section{LEGAL NOTICE}

This report was prepared as an account of Government sponsored work. Neither the United States, nor the Commission, nor any person acting on behalf of the Commission:

A. Makes any warranty or representation, expressed or implied, with respect to the accuracy, completeness, or usefulness of the information contained in this report, or that the use of any information, apparatus, method, or process disclosed in this report may not infringe privately owned rights; or

B. Assumes any liabilities with respect to the use of, or for damages resulting from the use of any information, apparatus, method, or process disclosed in this report.

As used in the above, "person acting on behalf of the Commission" includes any employee or contractor of the Commission, or employee of such contractor, to the extent that such employee or contractor of the Commission, or employee of such contractor prepares, disseminates, or provides access to, any information pursuant to his employment or contract with the Commission, or his employment with such contractor.

\section{PACIFIC NORTHWEST LABORATORY \\ RICHLAND, WASHINGTON \\ operated by}

BATTELLE MEMORIAL INSTITUTE

for the

UNITED STATES ATOMIC ENERGY COMMISSION UNDER CONTRACT AT(45-1)-1830 


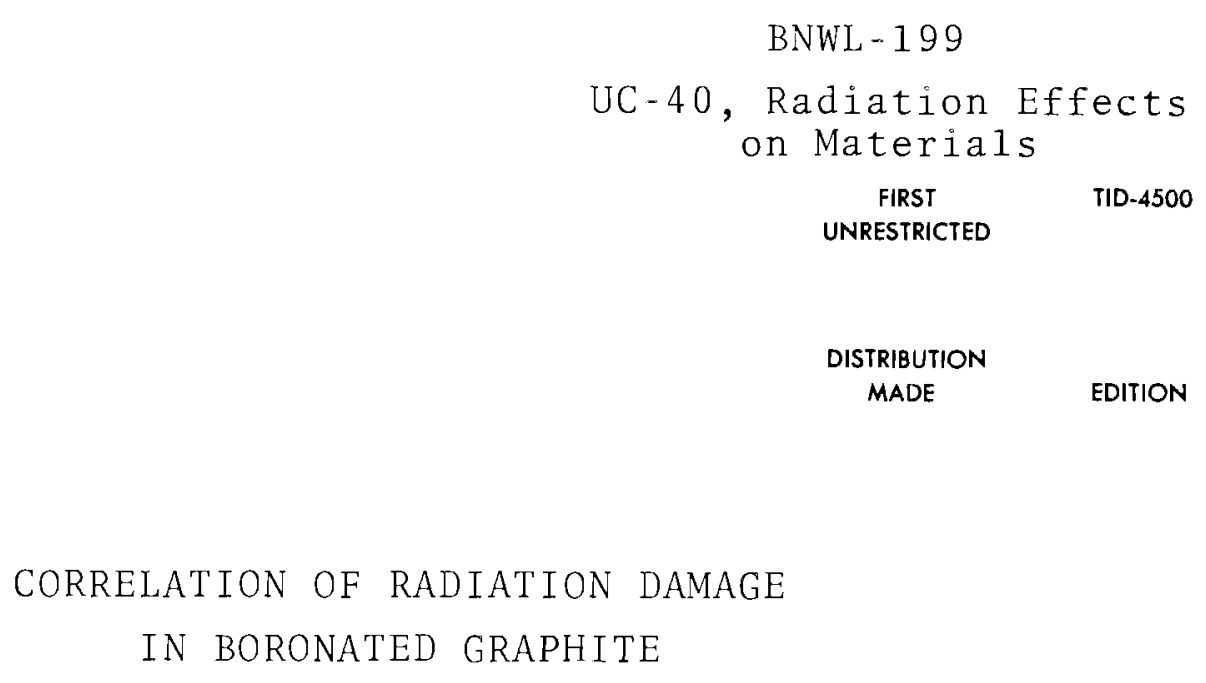

By

R. E. Dahl

Ceramics and Graphite Research Section

Materials Department

Frge vapertoro

DA PRW

MAR 8 'GR

February, 1966

PACIFIC NORTHWEST LABORATORY

RICHLAND, WASHINGTON 
Printed in USA. Price $\$ 2.00$. Available from the clearinghouse for Federal Scientific and Technical Information, National Bureau of Standards, U. S. Department of Commerce, Springfield, Virginia 


\section{TABLE OF CONTENTS}

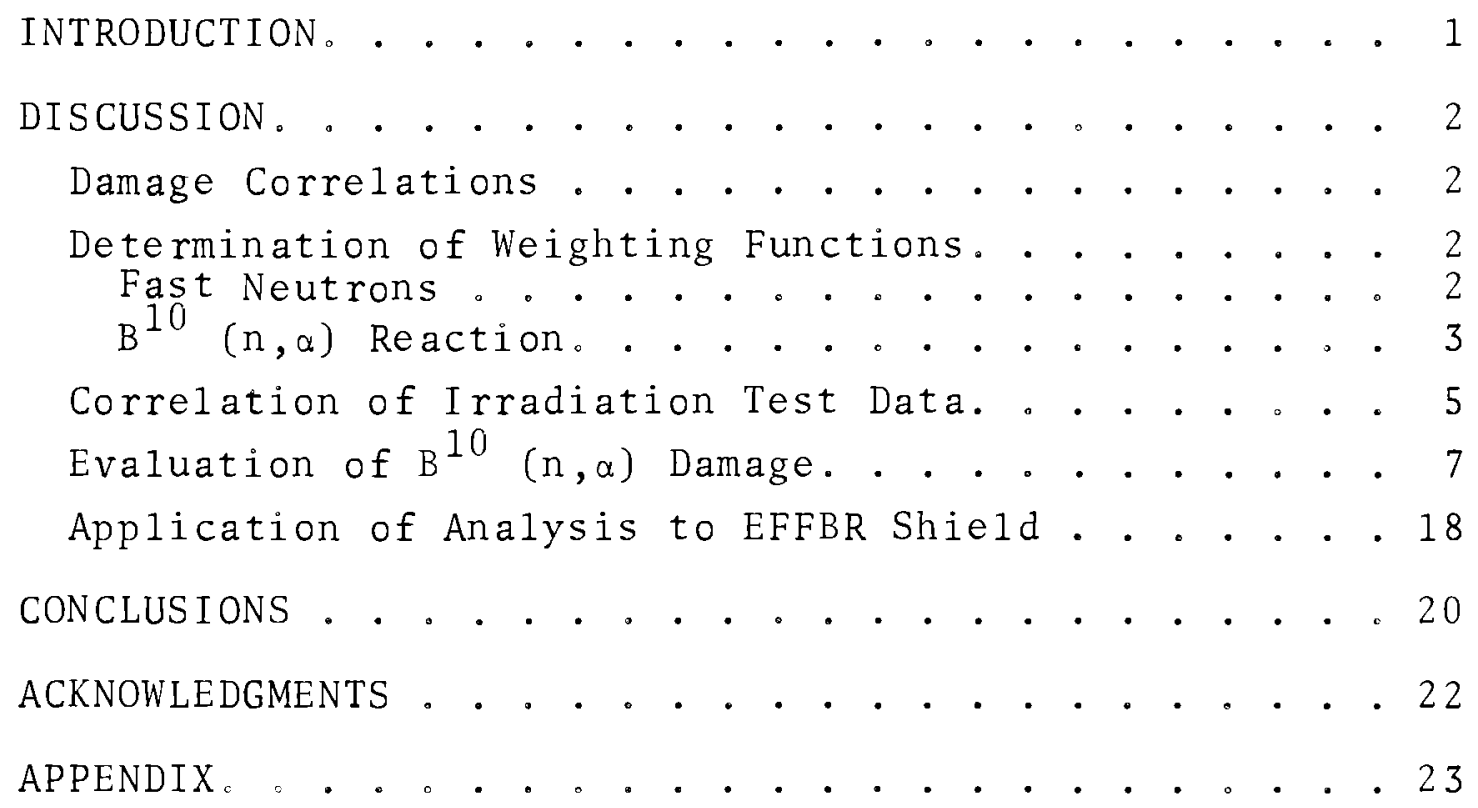



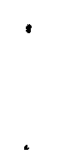


\section{CORRELATION OF RADIATION DAMAGE \\ IN BORONATED GRAPHITE}

\section{INTRODUCTION}

This report presents an analysis of the observed radia* tion damage caused by fast and thermal neutrons in the boronated graphite used for the shield in the Enrico Fermi Fast Breeder Reactor (EFFBR).

Boronated graphite has excellent potentialities as a fast reactor shield material. Neutrons are moderated and thermalized by the carbon and subsequently captured by boron. Boronated graphite possesses the structural and mechanical properties of nuclear graphite, is readily available, and is relatively inexpensive. However, before using the material in a fast re. actor shield, the effects of neutron radiation must be determined.

Radiation damage in boronated graphite is difficult to interpret because two processes operate in parallel to displace atoms and ultimately to damage the material. Displacements are caused by fast neutron collisions with atoms and by the products from the $\mathrm{B}^{10}(\mathrm{n}, \infty) \mathrm{Li}^{7}$ reaction which are emitted with a combined energy of $4.7 \mathrm{MeV}$. This reaction is caused by low energy neutrons and primarily by thermai neutrons. Thus, the extent to which each of these processes contributes to the total radiation effects will depend on the neutron spectrum. The relative effectiveness of each process will have to be understood particularly when one attempts to predict radiation effects in fast reactors from the results of tests conducted in thermal reactors.

Two grades of boronated graphite, black and gray, each containing either 4 or 7 wt $\%$ boron carbide $\left(\mathrm{B}_{4} \mathrm{C}\right)$, were ìradiated. Transverse and parallel orientations of each type were studied. The dimensional stability of boronated graphites dur. ing irradiation is of particular interest. Tests were conducted in thermal reactors, $(1,2)$ since no fast test reactors were 
available for materials testing, and because it is believed that data can be applied to the Fermi reactor problems if a careful analysis is made. Thus, if the damaging processes of fast and thermal neutrons can be correlated, the Hanford experiments can be used to predict the behavior of the Fermi shield.

DISCUSSION

Damage Correlations

Correlation of data for graphite irradiation in diverse spectra is based on the assumption that the effects produced in a given material at a given temperature are related to the number of carbon atoms displaced from lattice sites. Cascades of knock-on atoms can be caused in boronated graphite by two processes: the displacement of carbon atoms either by fast neutrons or by helium and lithium atoms formed in the reaction, $\mathrm{B}^{10}(\mathrm{n}, \alpha) \mathrm{Li}^{7}$. The latter effect is produced almost entirely by thermal neutrons. The relative effectiveness of fast and thermal neutrons in producing displacements is determined from the analysis of these two processes.

Determination of Weighting Functions

\section{Fast Neutrons}

Property changes (ie, damage) caused in diverse reactor spectra have been correlated by calculating and equating the lattice atom displacements produced. (3) The number of displacements, $D_{n}$, produced per cubic centimeter per second by fast neutrons is given by

$$
D_{n}=\sum_{0}^{\infty} \phi\left(E_{n}\right) \Sigma_{s}\left(E_{n}\right) N\left(E_{n}\right) d E
$$

where $\phi\left(E_{n}\right)$ is the neutron spectrum;

$\Sigma_{S}\left(E_{n}\right)$ is the macroscopic differential elastic scattering cross section of carbon; and

$N\left(E_{n}\right)$ is the number of displacements produced by 


\section{collision of a neutron of energy $\left(E_{n}\right)$ with} an atom.

Data obtained in several diverse spectra have been corre: lated by normalizing the exposures to neutrons above an energy $\mathrm{E}_{\mathrm{L}}$ chosen according to the equation:

$$
\bar{\Sigma}_{D}=\frac{\int_{0}^{\infty} \phi\left(E_{n}\right) \Sigma_{s}\left(E_{n}\right) N\left(E_{n}\right) d E}{\int_{E_{L}}^{\infty} \phi(E) d E}
$$

where $\bar{\Sigma}_{D}$ is the effective displacement cross section for carbon by neutrons above an energy $E_{L}$.

The lower integration limit, $E_{L}$, of the exposure normalization is varied until the same or nearly the same value for $\tilde{\Sigma}_{D}$ is obtained in each of the various spectra, $\phi(E)$. When this is accomplished, displacement production per unit exposure to neutrons with energies exceeding $E_{L}$ is the same regardless of the spectrum. An energy of $0.065 \mathrm{MeV}$ is the optimum value of $E_{L}$ for carbon. (3) However, the value of $0.18 \mathrm{MeV}$ (correspond. ing to a lethargy value of 4.0) has been used for several years in graphite studies at Hanford and leads to discrepancies of less than $10 \%$. This value of $\mathrm{E}_{\mathrm{L}}$ will therefore continue to be used. Thus, Equation (1) can be conveniently written as $\mathrm{D}_{\mathrm{n}}=\Phi(\mathrm{E}>0.18) \tilde{\bar{\Sigma}}_{\mathrm{D}}$ where $\Phi(\mathrm{E}>0.18)$ is the energy integrated flux density from 0.18 to $10 \mathrm{MeV}$.

\section{$\underline{B^{10}(n, \alpha) \text { Reaction }}$}

Damaged produced by a $B^{10}(n, \alpha)$ reaction can be estimated if two basic assumptions are valid: (1) the observed property change caused by the reaction is proportional to the number of displaced carbon atoms, and (2) the energetic lithium and helium atoms produced by the reaction act as primary knock=on atoms in 
causing displacement cascades.

The number of displacements caused by a $B(n, \alpha)$ reaction is derived in the Appendix. From this analysis it was estimated that the $\mathrm{He}^{4}$ atom, emitted with an energy of $0.8 \mathrm{MeV}$, initiates a cascade which ultimately displaces about 500 carbon atoms and a $\mathrm{Li}^{7}$ atom, emitted with an energy of $0.45 \mathrm{MeV}$, ultimately displaces about 800 carbon atoms. Thus, approximately 1300 atoms are estimated to be displaced by each reaction.

The number of carbon atoms displaced per cubic centimeter per second, $\left(D_{B}\right)$, by the $B^{10}(n, \alpha)$ reaction is then calculated by:

$$
D_{B}=N_{B} \int_{0}^{\infty} \phi(E) \Sigma_{a}(E) d E
$$

where $\Sigma_{a}$ is the macroscopic absorption cross section of boron; and $\mathrm{N}_{\mathrm{B}}$, the number of displacements caused by the reaction, has a value of 1300. In this analysis $N_{B}$ does not vary with neutron energy since the energy of neutrons producing most of the reactions is negligible compared tothe $Q$ value of the reaction.

The degree of boron dispersion in boronated graphite strongly influences the magnitude of produced effects. Boron atoms in the graphite lattice will produce a relatively large number of displaced carbon atoms, and the resulting disorder will be comparable to that caused by a fast neutron collision with a graphite lattice atom. However, damaged produced by boron atoms in $\mathrm{B}_{4} \mathrm{C}$ particles will be contained principally within the particles and will have little influence on the bulk properties.

An analysis of damage caused by boron atoms in $\mathrm{B}_{4} \mathrm{C}$ particles is made in the Appendix (See section on boron dispersion). It is concluded that the number of displaced atoms produced by reaction of boron atoms in $\mathrm{B}_{4} \mathrm{C}$ particles will be 1 ess than $5 \%$ of the number caused by the same number of boron atoms in solid 
solution in the graphite crystals. Therefore, in the analysis of radiation effects in boronated graphite, the boron in $\mathrm{B}_{4} \mathrm{C}$ particles are assumed to have no effect on the bulk properties during irradiation.

If all the boron were present as $\mathrm{B}_{4} \mathrm{C}$, the bulk material would respond differently to the neutron bombardment than if particulate matter were not present to disturb the structure. Irradiation of a graphite containing inert particles (eg, SiC) having a size relative to that of $\mathrm{B}_{4} \mathrm{C}$ would be helpful in analyzing radiation effects in boronated graphite.

Phase diagrams (4) indicate that the maximum amount of boron that can go into solid solution at the manufacturing temperature of the Fermi boronated graphite is approximately $2 \%$ if equilibrium were obtained. During cooling, some boron remains in solution while the excess precipitates as $B_{4} C$. Thus, the amount of boron in solid solution will depend on the temperature history of the specimen.

Therefore, boron dispersion should be considered in the damage analysis by modifying Equation (3) to include a term which would effectively reduce displacement production by an amount proportional to the fraction of boron as boron carbide particles. Thus, displacements are calculated as

$$
D_{B}=A N_{B} \int \phi(E) \Sigma_{a}(E) d E
$$

where $A$ is the effective boron fraction and $0 \leq A \leq 1$.

The fraction of "effective" boron in solid solution will be evaluated empirically. Values of A vary significantly across sample bars because of processing variations; thus, the values which have been calculated represent gross averages.

Correlation of Irradiation Test Data

Irradiation test data can be correlated if the preceding analysis is valid. Damage from fast neutrons can be estimated if the flux of neutrons with energies exceeding $0.18 \mathrm{MeV}$ can be 
determined; and damage from the reaction, $\mathrm{B}^{10}(\mathrm{n}, \alpha) \mathrm{Li}^{7}$, can be estimated if the value of $A$ is evaluated for each type of material. Estimation of damage from the $B^{10}(n, \alpha)$ reaction will be simplified initially by assuming that the reaction is caused only by thermal neutrons.

With the above approximations and the further assumptions that: (1) a displacement from the $B^{10}(n, \alpha)$ reaction, $D_{B}$, causes the same property change as a displacement from fast neutrons in $\mathrm{D}_{\mathrm{n}}$; and (2) helium gas formation does not contribute substantially to property change, the property changes should be proportional to the number of displacements as calculated by

$$
\mathrm{D}=\mathrm{D}_{\mathrm{n}}+\mathrm{D}_{\mathrm{B}}
$$

where

$$
D=\left[\phi(E>0.18) \bar{\Sigma}_{D}+\phi_{t h} A \Sigma_{a} N_{B}\right] t .
$$

In order to apply Equation (5), its terms must be evaluated. Displacement production from fast neutron collisions with carbon atoms can be calculated if the flux above $0.18 \mathrm{MeV}$ is determined. The effective displacement cross section, $\bar{\Sigma}_{D}$ (Equation 2), has a value of 244 for boronated graphite having a density of $1.7 \mathrm{~g} / \mathrm{cm}$ and has been found to be nearly constant for neutron spectra in light water and graphite moderated reactor which have been studied to date.

The bulk damage contribution of the displacements caused by $B^{10}(n, \alpha)$ reaction will be estimated from Equation (5). For boronated graphite with a density of $1.7 \mathrm{~g} / \mathrm{cm}^{3}$ and 6 wt: natural boron, the absorption cross section (reaction cross section) is

$$
\Sigma_{\mathrm{a}}=\sigma_{\mathrm{a}} \mathrm{N}_{\mathrm{o}} \mathrm{\rho}
$$

where $\sigma_{\mathrm{a}}=775 \times 10^{-24} \mathrm{~cm}^{2}$, and

$\mathrm{N}_{\mathrm{O}}=\frac{6.023 \times 10^{23} \times 1.7 \times 0.06}{11}=5.58 \times 10^{21}$ atoms $/ \mathrm{cm}^{3}$.

The number of displacements per reaction of boron $\mathrm{N}_{\mathrm{B}}$ which is in solution is approximately 1300. Therefore, 


$$
\begin{aligned}
N_{B} & =\left(755 \times 10^{-24}\right)\left(5.58 \times 10^{21}\right)\left(1.3 \times 10^{3}\right) \\
& \simeq 5500 \frac{\text { displacements }}{\text { neutron-cm }} .
\end{aligned}
$$

Thus,

$$
\mathrm{D}_{\mathrm{B}}=\left[(240) \phi(\mathrm{E}>0.18)+5500 \mathrm{~A} \phi_{t h}\right] t \frac{\text { displacements }}{\mathrm{cm}^{3}} .
$$

Evaluation of $B^{10}(n \alpha)$ Damage

Data can be correlated between diverse neutron spectra if values of A can be determined for the boronated graphites studied. In this investigation, the irradiation tests conducted in the $2 \mathrm{C}$ facility $(1)$ in a graphite moderated reactor and those conducted in the ETR ${ }^{(2)}$ provided a means to determine a value of $A$ and apply the data to the EFFBR. The ratio of thermal-tofast flux in the Hanford $2 \mathrm{C}$ test facility ${ }^{(1)}$ was about 8.3. This ratio in the ETR shielded tests ${ }^{(2)}$ (GEH-23-13 and 23-16) was 0.08 . Thus, very different ratios of fast-to-thermal neutron induced damage are produced. The GEH-23-8 experiment was an unshielded experiment in the ETR in which the thermal-to-fast ratio is approximately 1.0 thus providing a third spectral variation. Data were correlated by assuming that equal numbers of lattice displacements are produced in samples exhibiting the same dimensional change when irradiated at the same temperature. $B^{10}(n, \alpha)$ damage was estimated in the $2 \mathrm{C}$ and ETR tests for each type of boronated graphite, black and gray, by calculating the value of A according to

$$
\begin{aligned}
{[240 \phi(\mathrm{E}>0.18)+} & \left.5500 \mathrm{~A} \phi_{t h}\right]_{2 \mathrm{C}}= \\
& {\left[240 \phi(\mathrm{E}>0.18)+5500 \mathrm{~A} \phi_{t h}\right]_{\mathrm{ETR} .} }
\end{aligned}
$$

Thus,

$$
A=0.04\left[\frac{\phi(E>0.18) \text { ETR }-\phi(E>0.18) 2 C}{\phi_{\text {th } 2 C-\phi}-\phi \text { ETR }}\right] .
$$


Data yield values for $A$ of about 0.039 for the gray material and 0.016 for the black. These yields indicate that $21 / 2$ times as much effective boron is in the gray material as in the black.

The value of A for black material was calculated from 5\% transverse data (Figure 1) from the $2 \mathrm{C}$ and GEH-23-16 samples and then was applied to 5\% parallel (Figure 2), 7\% transverse (Figure 3), and $7 \%$ transverse (Figure 4) samples from the remainder of the tests. The value of A was similarly obtained for gray material; ie, 5\% transverse (Figure 5), 5\% parallel (Figure 6), $7 \%$ transverse (Figure 7), and $7 \%$ parallel (Figure 8). Thus the value of $A$ was obtained from one set of data and tested on the other sets for both black and gray material.

The relative damaging ratio of fast neutron displacements to those caused by $B^{10}(n, \alpha)$ reaction in the $2 \mathrm{C}$ and ETR experiments can be deduced from Equation (6). For black material, the number of displacements is

$$
\begin{aligned}
& D=\left[244_{\phi f}+76_{\phi t h}\right] \\
& \text { and for gray it is } \\
& D=\left[244_{\phi f}+188_{\phi t h}\right] .
\end{aligned}
$$

In the $2 \mathrm{C}$ facility the ratio of thermal-to-fast flux is 8.3:1; thus, for the black boronated graphite, the number of displacements is

$$
D=244 \phi_{f}+76(8.3) \phi_{f},
$$

or the ratio of the number of displacements caused by thermal neutrons to that caused by fast neutrons is

$$
(76)(8.3) / 244=2,6: 1 \text {. }
$$

For gray boronated graphite the corresponding number would be

$$
D=244+188(8.3) ;
$$




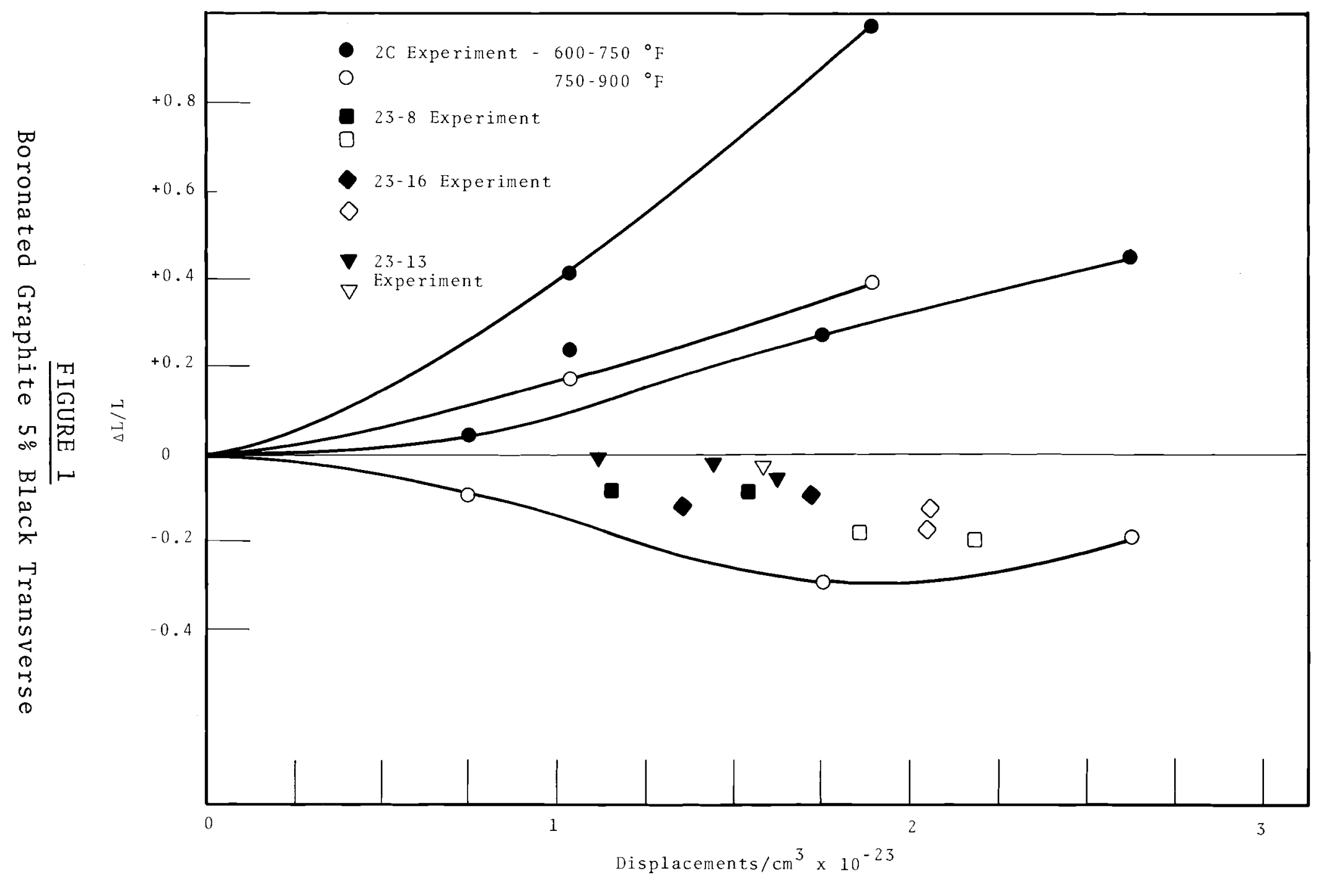

6 


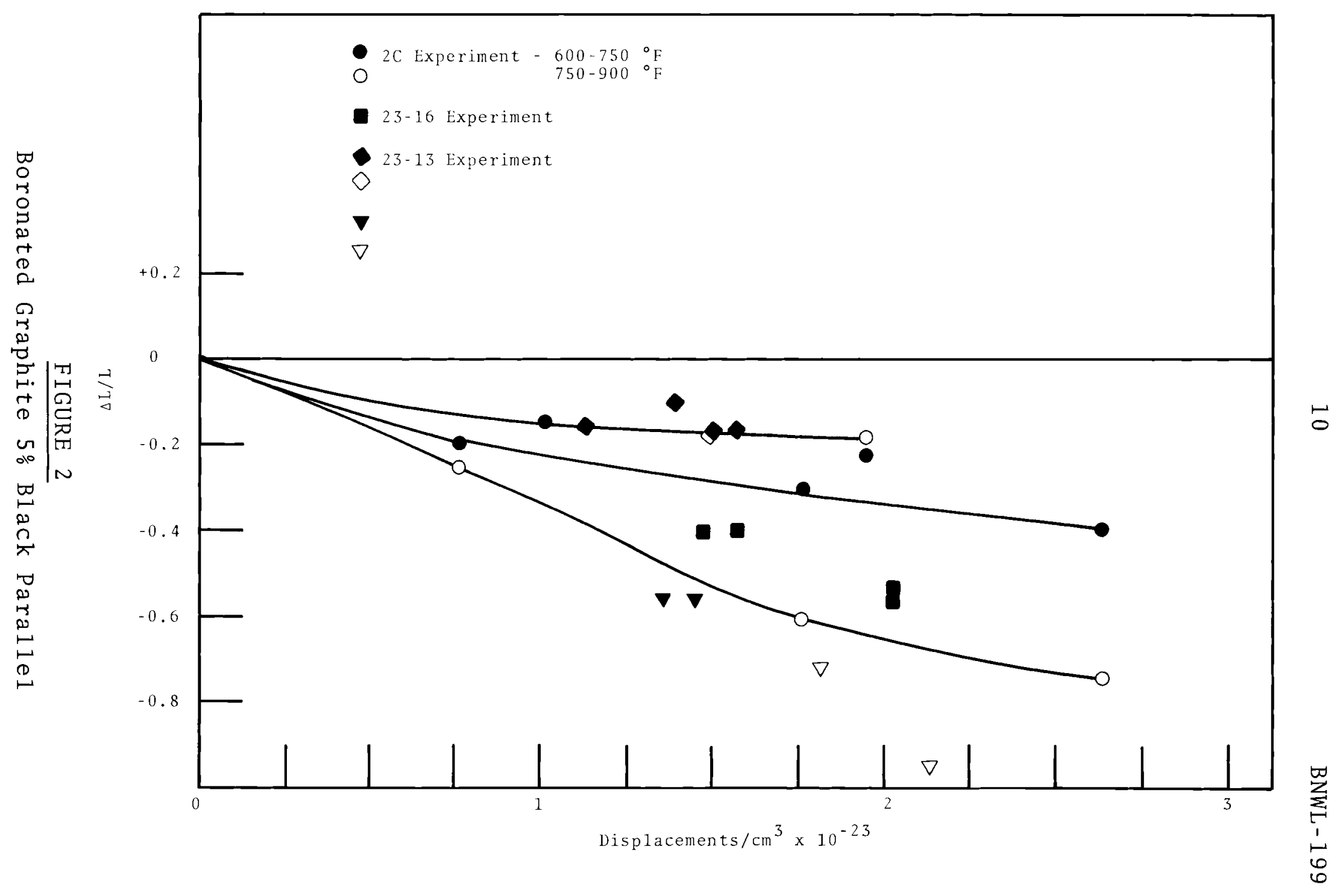




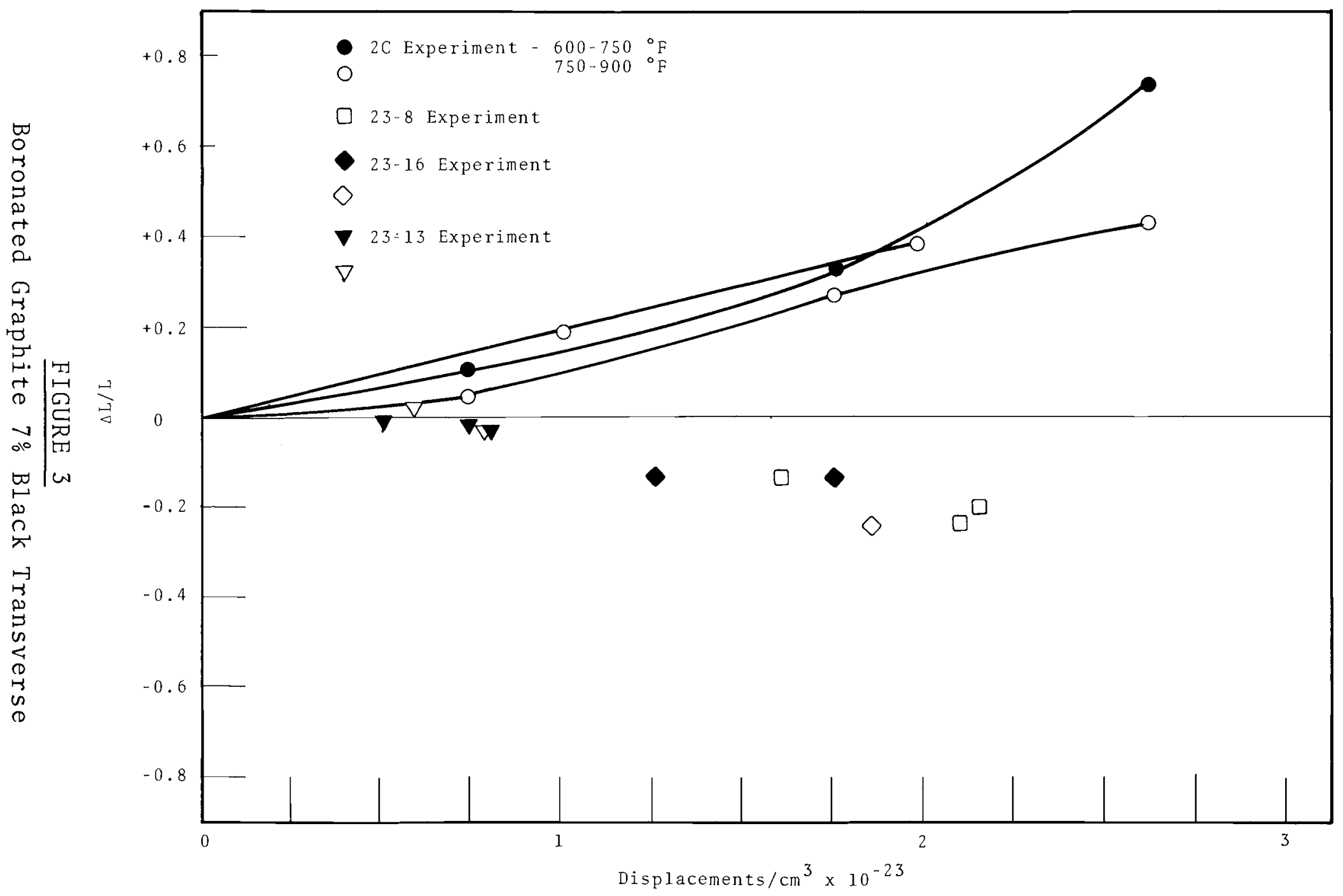




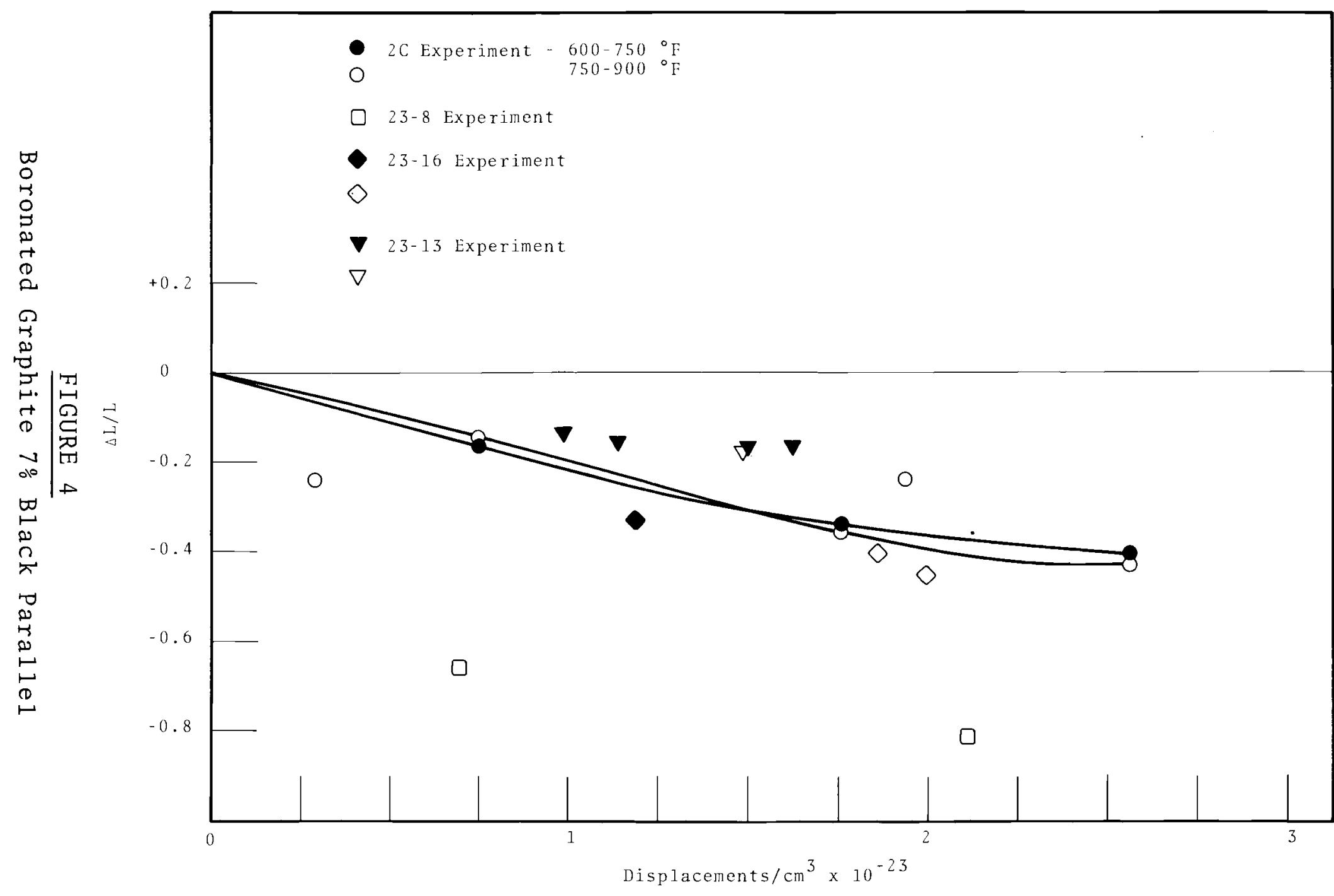

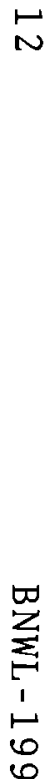




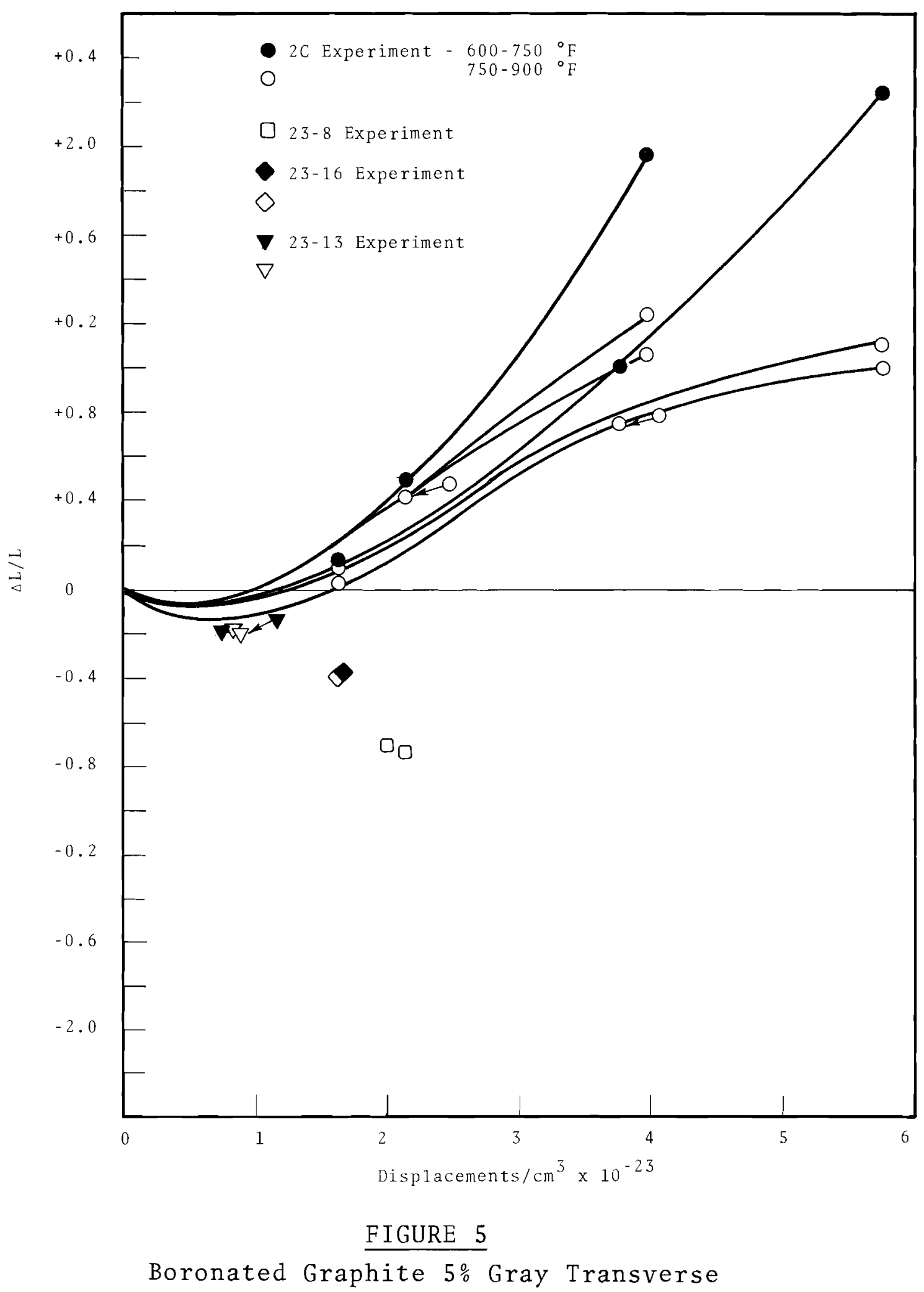




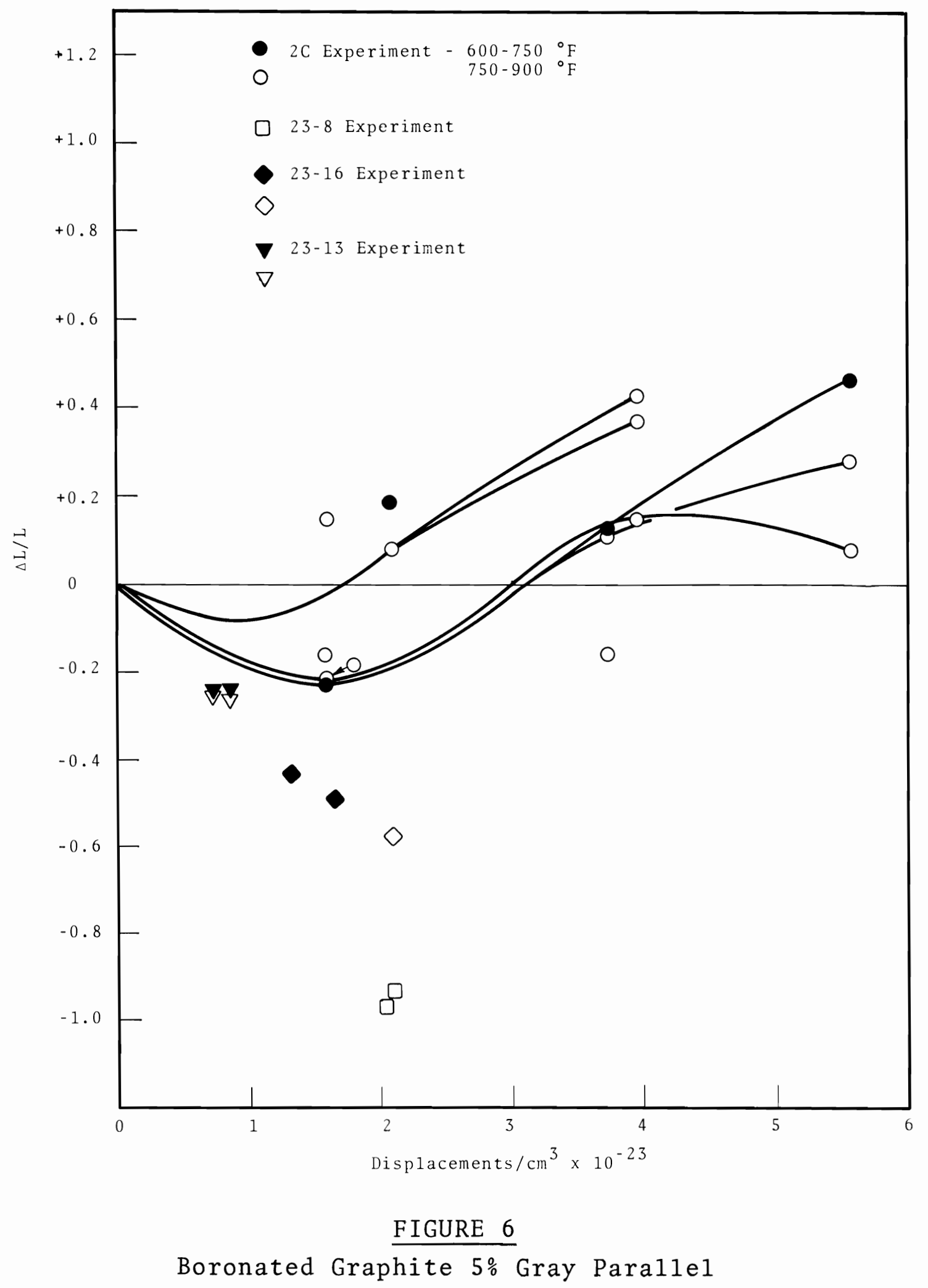




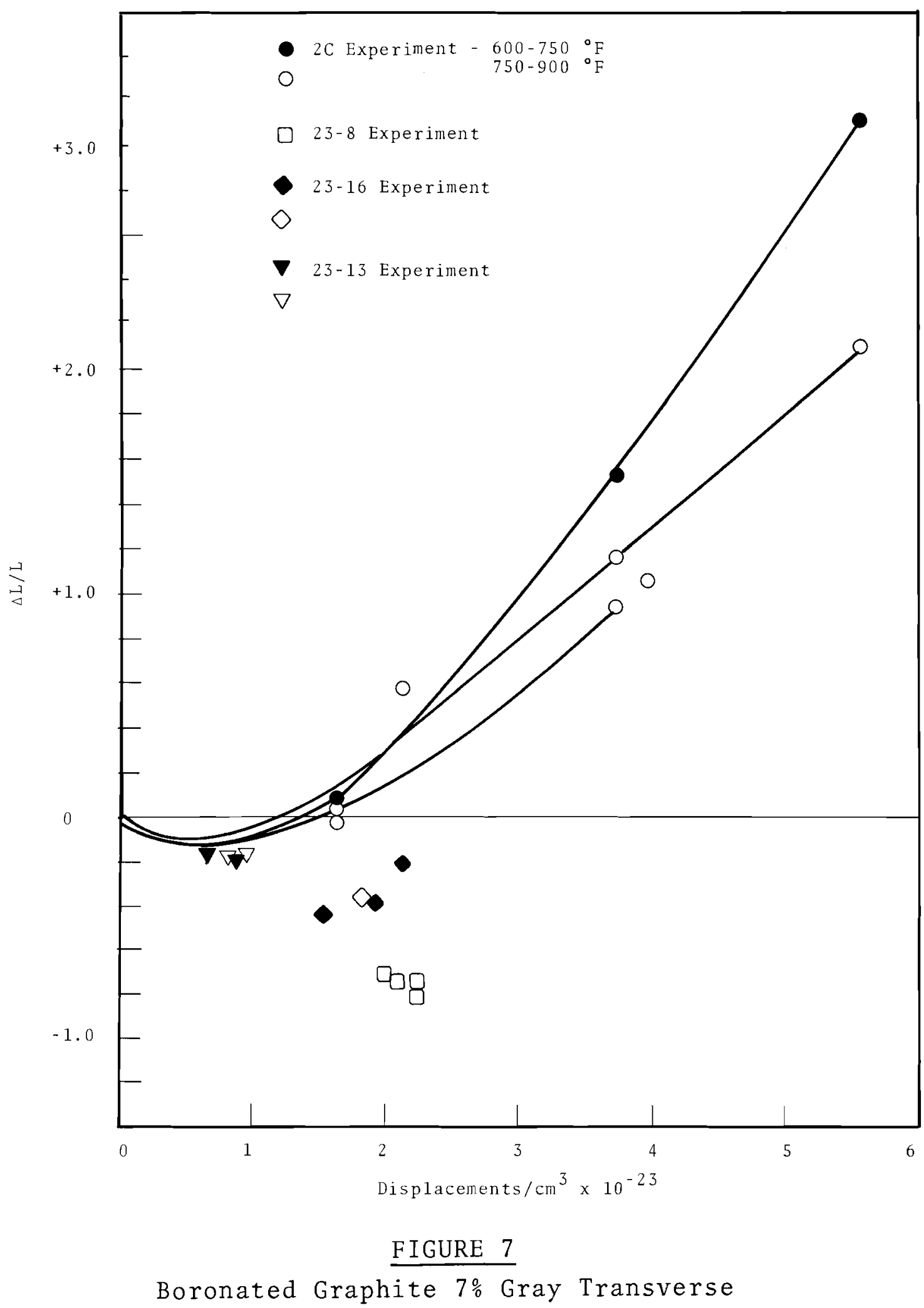




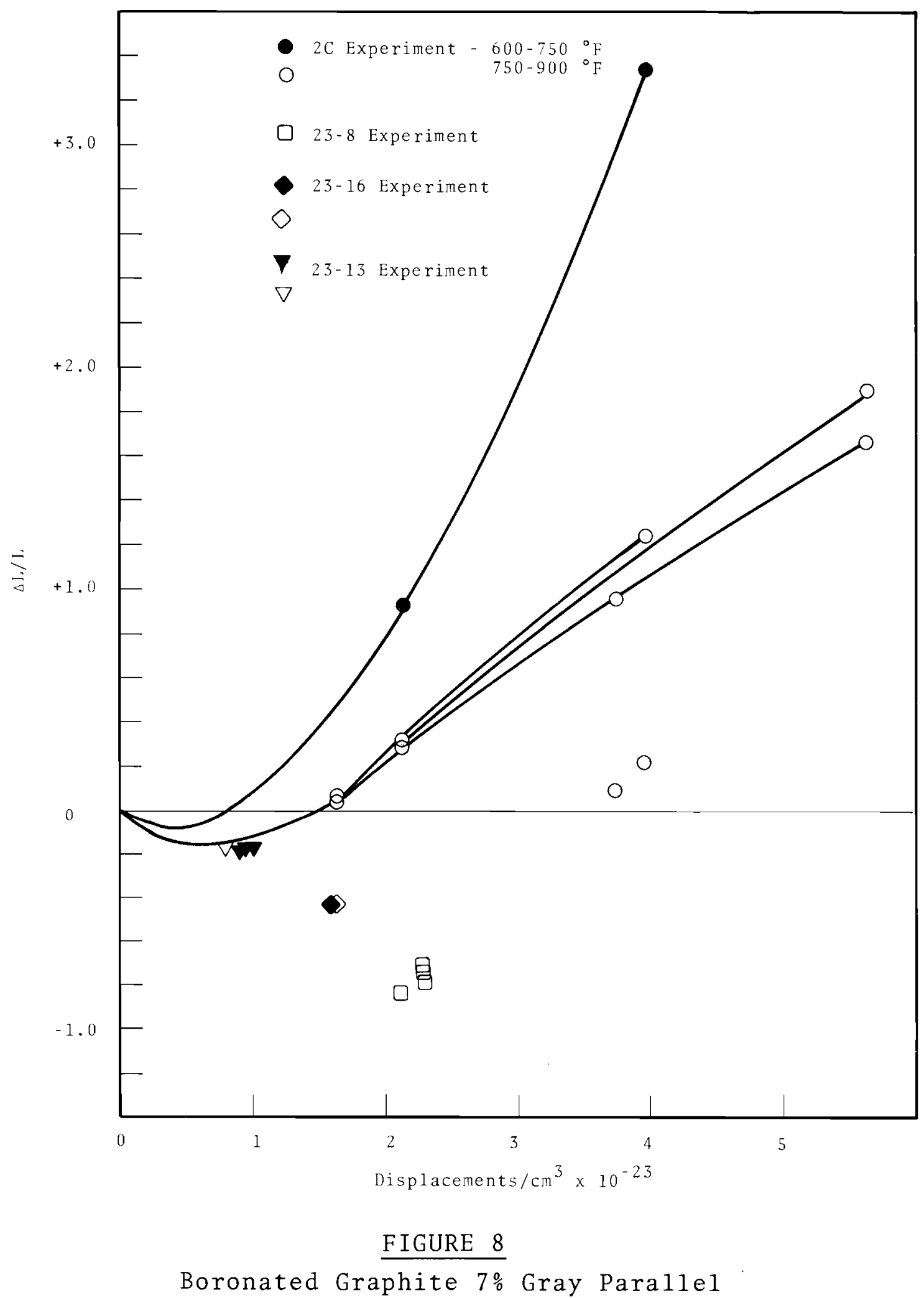


thus, the corresponding ratio of number of displacements would be

$$
188(8.3) / 244=6.4: 1 \text {. }
$$

These calculated ratios are in satisfactory agreement with the ratios determined experimentally in the Hanford $2 \mathrm{C}$ facility in which a right cylindrical boronated graphite sample was fitted into a sleeve of the same material. (6) The ratio of expansion of the sleeve to that of the cylinder was $2: 1$ for black graphite and $8: 1$ for gray.

In the ETR shielded tests (23-13 and 23-16), fast neutrons cause nearly all of the displacements. According to the analysis for black boronated graphite, the number of displacements is

$$
D=[244] \times 1+76(0.08)]
$$

or $D_{n} / D_{B}=40: 1$,

and for the gray samples:

$$
\begin{aligned}
& D=(244 \times 1)+(188 \times 0.08) \\
& \text { or } D_{n} / D_{B}=17: 1 \text {. }
\end{aligned}
$$

Reasonably good correlation between the $2 \mathrm{C}$ experiments and the shielded ETR experiments was obtained for the black material. Parallel samples of both 5 and $7 \%$ black showed the same behavior on an exposure scale normalized to displacements. However, behavior of $7 \%$ black transverse could not be satisfactorily normalized since all irradiated samples in the ETR contracted while those irradiated in the $2 \mathrm{C}$ facility expanded.

In the gray samples irradiated in the Hanford $2 \mathrm{C}$ experiments, the length passed through a minimum at relatively low exposures and then expanded rapidly with increasing exposure. All of the gray samples irradiated in the shielded ETR experiments contracted. The dimensional changes are comparable in magnitude to the contractions of the samples, irradiated in $2 \mathrm{C}$, before they began to expand. The method of correlation would 
be substantiated if further irradiation in the ETR facility caused the samples to expand. Some evidence of this is seen in the $7 \%$ gray transverse data. However, if contraction continued with increased exposure, the predominance of another damage mechanism would be established.

Mechanisms which cause damage to boronated graphite other than disorder from displacement cascades are probable: Genera= tion of helium pressure from the $B^{10}(n, a)$ reaction is one possible cause why samples irradiated in a high thermal flux expand while those irradlated in a fast flux contract. However, this possibility seems remote since graphite is very permeable to helium.

Another possibility may be that lattice displacements may nucleate and anneal differently if they are produced randomiy throughout the specimen rather than in a highly disordered "buffer" zone surrounding boron-carbide particles.

Application of Analysis to EFFBR shield

Neutron spectra, rates of fast neutron displacement production, and displacements from $B^{10}(n, \alpha)$ reactions were calculated for the EFFBR shield and for samples irradiated in the Hanford 2C facility.

A profile of displacement production for a specimen irradiated in the 2C facility which has no burnout of boron (Figure 9) demonstrates that the principal damaging process is the $\mathrm{B}^{10}(\mathrm{n}, \boldsymbol{x})$ reaction. The ratio of total displacements produced in the sample by boron reactions to those produced by fast neu= trons, $D_{B} / D_{n}$, is 14 . The displacement gradient is very steep because the $\mathrm{B}^{10}(\mathrm{n}, \alpha)$ damage predominates and self-shielding within the boronated graphite specimen is very important. There is no gradient in fast neutron damage across the specimens because the diameter of the sample is much less than the mean free path of a fast neutron. As this analysis includes cross sections for the $B^{10}(n, \alpha)$ reaction is therefore, overestimated. However, when the effect of nonuniform boron dispersion is included 


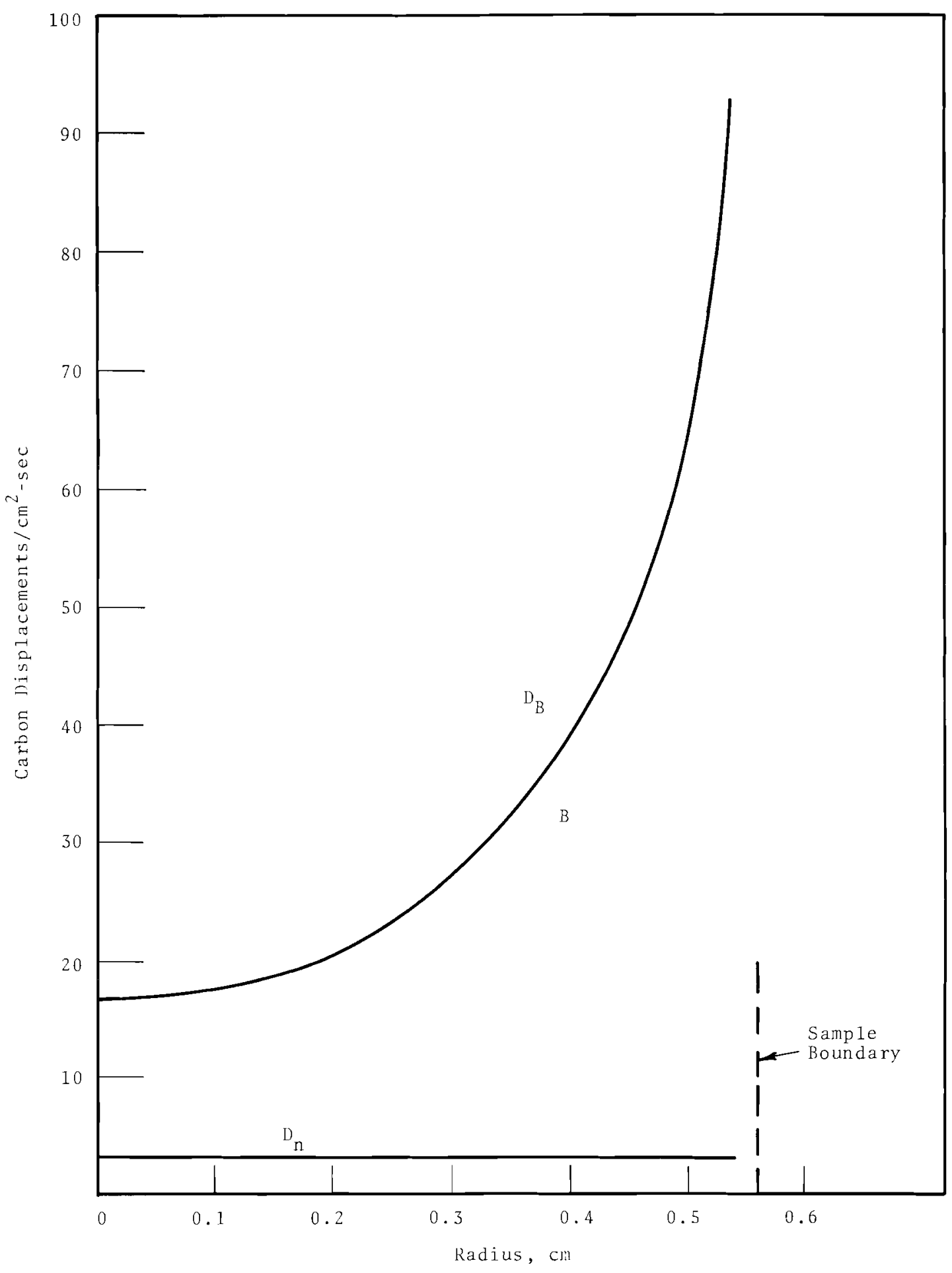

Carbon Displacement $\mathrm{s} / \mathrm{cm}^{2}-\mathrm{sec}$ 
in the analysis, the two processes cause approximately equal damage.

A similar analysis is made for the inner boronated graphite region of the EFFBR shield, and results are presented in Figure 10. In this case the ratio of displacements, caused by the fast neutrons, to those caused by boron reactions was 113:1 in the boronated graphite region, when the effect of boron dispersion was not considered. When boron dispersion is included, the ratio is nearly 3000:1, thus, 1ndicating that there will be no appre. ciable effect caused by $B^{10}(n, \alpha)$ reactions. Since this is the case, self-shielding does not produce a damage gradient, and the damage gradient of 14 across the $13 \mathrm{~cm}$ region is proportional to the fast flux gradient.

CONCLUSIONS

The method developed in this study is considered adequate to establish limits for dimensional changes which will occur in the EFFBR shield by using radiation effects in boronated graphite observed in irradiation tests. Dimensional changes observed in the tests are at exposures which are calculated to equal or exceed those which will be received in the EFFBR shield.

However, use of the analysis to verify postulates on dis placement mechanisms or to extrapolate predictions beyond the present exposure levels is not justified by the data correlations made to date. Additional data at higher exposures would verify or refute the assumption that the samples irradiated in a flux with a low thermal-to-fast ratio would expand after initial contracting. Thereby, these data would correlate with the expansion of samples irradiated in a flux with a low thermal-tofast ratio.

The analysis performed for the inner boronated region in tha EFFBR shield indicates that the fast neutron induced displacements are the predominant damaging mechanism. There is no selfshielding with this process. Hence, there is not the extreme 


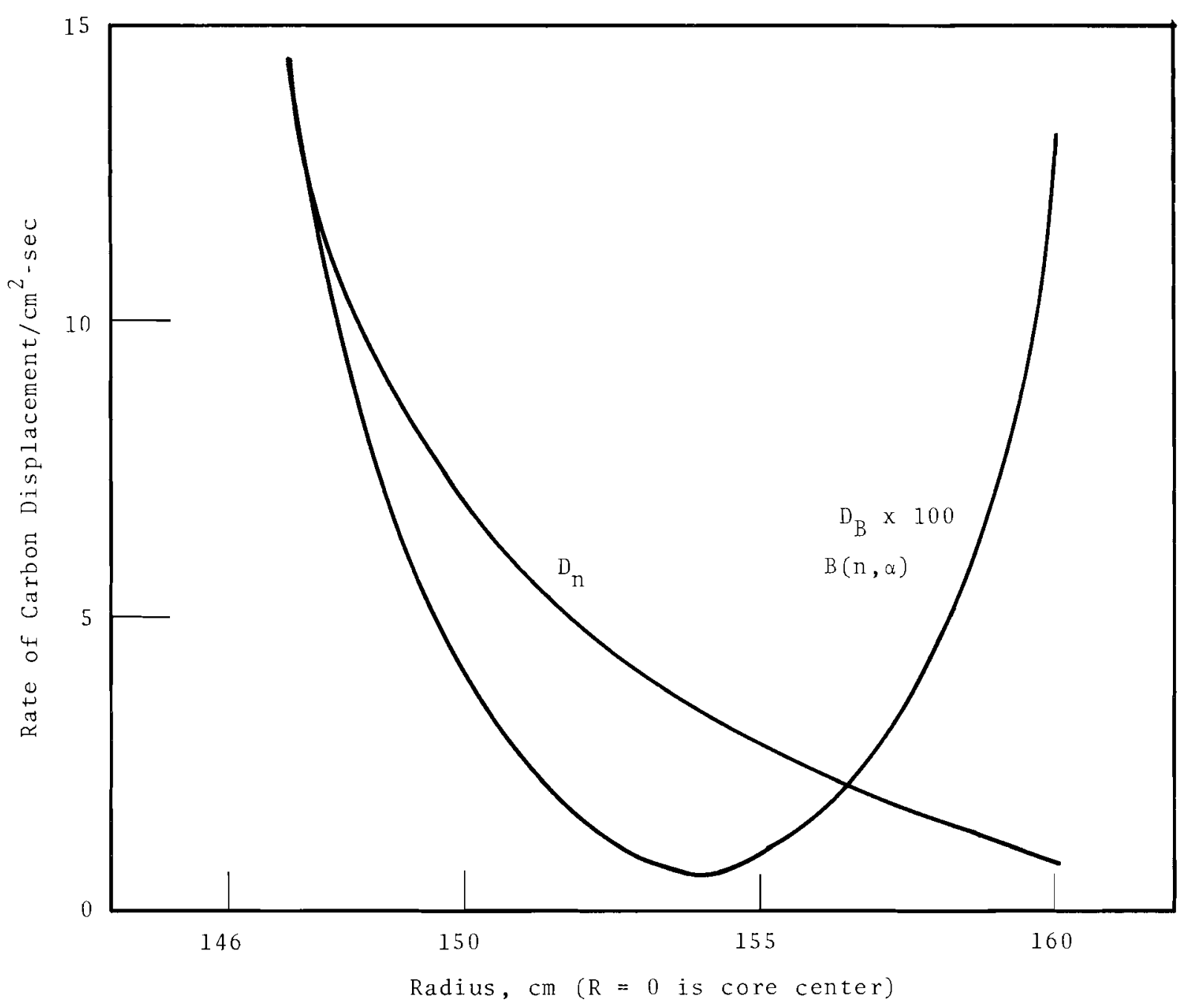

FIGURE 10

Displacements in the Boronated Region of the Fermi Reactor 
damage gradient characteristic of the $B^{10}(n, \alpha)$ reaction. ACKNOWLEDGMENTS

The author is grateful for the continued help received from $J$. A. Ulseth in all phases of this study, and for the help received from J. C. Stouffer and Dr. J. B. Goebel in developing a method and computer program to calculate the affect of particulate $\mathrm{B}_{4} \mathrm{C}$ on radiation damage in boronated graphite.

Discussions with Dr. H. H. Yoshikawa were particularly helpful in guidance of the study. The cooperation and valuable help received from J. M. Davidson, L. O. Gates, and R. Neidner who were responsible for the irradiation programs was essential. 


\section{APPENDIX}

An analysis of radiation effects in boronated graphite depends on determining the number of displacements caused by collisions of fast neutrons with carbon atoms relative to the number of displacements causec by $B^{10}(n, \alpha)$ reactions. For the analysis the following assumptions will be made:

1. Damage (dimensional changes) induced by neutron irradiation may be related to the total number of displaced carbon atoms.

2. The helium and 1 ithium atoms which are the products of the $B^{10}(n, \alpha) L^{7}$ reaction will act as primary knock-on atoms in initiating displacement cascades of carbon atoms. The magnitude of the cascades can be calculated from carbon displacement models with appropriate corrections for atomic charge, mass, and energy.

The basic data to be used in this analysis are

Initial energy $\left(E_{p}\right) \mathrm{MeV}$ Path length $(\rho)$, microns Atomic mass (M)

Atomic charge (Z) Displacement $\left(E_{D}\right)$ energy, eV

The method outlined by Dienes and Vineyard ${ }^{(6)}$ will be used to determine scattering modes and finally to calculate displacement production.

Scattering Mode

It must be determined whether the carbon atom, scattering from $\mathrm{He}^{4}$ and $\mathrm{Li}^{7}$, obeys either the Rutherford or the hard-shell scattering laws, and the distinction must be determined. 
Elastic collisions are of Rutherford type when the energy of the moving atom, $E$, is much greater than a critical energy (ie, $\left.E \cdot E_{A}\right)$. These collisions are approximately the hard-sphere type when $\mathrm{E}<<\mathrm{E}_{\mathrm{A}}$.

The critical energy, $E_{A}$ (following the treatment of Dienes and Vineyard) is

$$
E_{A}=E_{R}\left[2\left(M_{1}+M_{2}\right) / M_{2}\right] z_{1} z_{2} \sqrt{Z_{1} 2 / 3+z_{2} / 3}
$$

where $E_{R}$ is the Rydberg Energy $=13.6 \mathrm{eV}$.

For $\mathrm{He}^{4}, \mathrm{C}^{12}$ collisions,

$$
\mathrm{E}_{\mathrm{A}}=13.6[2(4+12) / 12] \text { (2) (6) } \sqrt{22 / 3+62 / 3}=1800 \mathrm{eV}
$$

Since the energies of the $\mathrm{Li}^{7}$ and $\mathrm{He}_{4}$ atoms are much greater than $1800 \mathrm{eV}$, the above collisions are of the Rutherford type with low energy transfers probable.

To calculate the mean number of displacements per primary displaced atom collision $(\bar{v})$, consider the primary displaced atom which will cause displacements in a carbon matrix:

$$
i=\bar{G} / 2 E_{D}
$$

where $G$ is that part of the energy of the primary knock-on atom that is expended in elastic collisions.

However, for light elements, a good approximation can be made by setting $\bar{G}$ equal to the ionization energy,

$$
\stackrel{\pi}{G}=E_{1}
$$

and by determining the ionization energy according to:

$$
E_{i}=M \times 10^{3} \mathrm{eV} \text {. }
$$

Thus for, $\mathrm{He}^{4}: \bar{v}=4 \times 10^{3} 2(25)=80$

$$
\begin{array}{ll}
\mathrm{Li}^{7}: & \bar{v}=7 \times 10^{3} / 2(25)=140 \\
\mathrm{C}^{12}: & \bar{v}=12 \times 10^{3} / 2(25)=240 .
\end{array}
$$


The preceding calculations indicate that the number of displacements will be proportional to the mass of the moving atoms. Therefore, a $\mathrm{He}^{4}$ atom at a given energy will cause 4/12 as many displacements as a carbon atom of the same energy; similarly, a $\mathrm{Li}^{7}$ atom will cause $7 / 12$ as many as a carbon atom when both have the same energy.

Carbon displacement production as a function of neutron energy can be estimated using a displacement theory model. The Kinchin and Pease model, (7) which has been used in this analysis, relates energy of the displaced carbon atom to neutron energies by:

$$
\overline{\mathrm{T}}=\mathrm{f}\left[2 \mathrm{M}_{1} \mathrm{M}_{2} /\left(\mathrm{M}_{1}+\mathrm{M}_{2}\right)\right] \mathrm{E}_{n}
$$

where $\overline{\mathrm{T}}$ is the mean energy transferred, and

$f$ is a factor correcting for anisotropy and

inelastic scattering. (For fast neutron bombardment

$f \simeq 2 / 3$. )

Thus, for neutron bombardment of carbon, the mean transferred energy

$$
\begin{aligned}
\overline{\mathrm{T}} & =2 / 3\left[\frac{2(1)(12)}{1+(12)} 2\right] \mathrm{E}_{n} \\
& =0.095 \mathrm{E}_{n} \cong 1 / 10 \mathrm{E}_{n}
\end{aligned}
$$

Thus, a $0.8 \mathrm{MeV}$ carbon knock-on atom would be caused by a neutron of $8 \mathrm{MeV}$. Similarly a $0.45 \mathrm{MeV}$ carbon knock-on atom would be caused by a $4.74 \mathrm{MeV}$ neutron. According to Kinchin and Pease model, with neutrons with energies of $8.42 \mathrm{MeV}$, and $4.74 \mathrm{MeV}$ cause about 1500 displacements.

From this relationship the number of displacements produced by carbon atoms with the kinetic energy of the $\mathrm{Li}^{7}$ and $\mathrm{He}^{4}$ products of the $B^{10}(n, \alpha)$ reaction can be calculated. The mass differences will be used to calculate the number of displacements 
actually caused by the $\mathrm{He}^{4}$ and $\mathrm{Li}^{7}$ atoms. Therefore, a $\mathrm{He}^{4}$ atom with $0.8 \mathrm{MeV}$ energy will cause:

$(1500)(4 / 12)=500$ displacements;

and a $\mathrm{Li}^{7}$ atom with $0.45 \mathrm{MeV}$ energy will cause

$(1445)(7 / 12)=900$ displacements.

The total displacements caused by the $B^{10}(n, \alpha)$ reaction is the sum of the displacement of its products,

$500 \cdot 900=1400$ displacements,

if both fragments interact only with lattice carbon atoms.

Effects of Boron Dispersion

Microscopic examination of boronated graphite specimens has shown that some of the boron exists in discrete $\mathrm{B}_{4} \mathrm{C}$ particles. However, in this study, the only concern is with displacements which occur in the graphite lattice and cause bulk damage. Therefore, if a $B^{10}(n, \alpha)$ reaction took place in a $B_{4} C$ particle at a distance greater than the mean path length of either the $\mathrm{He}^{4}$ atom or the $\mathrm{Li}^{7}$ atom from the surface of the particle, the displacements caused would be contained within the particle and would not affect the bulk properties. If boron is concentrated in $\mathrm{B}_{4} \mathrm{C}$ particles, the net effect will be a reduction of the contribution of the $B^{10}(n, \alpha)$ reactions.

To analyze the effects of $\mathrm{B}_{4} \mathrm{C}$ particles on displacement production, the following assumptions are made:

1. The geometry of the $\mathrm{B}_{4} \mathrm{C}$ particles can be approximated as spheres.

2. The $\mathrm{B}_{4} \mathrm{C}$ particles will in general have diameters ranging from 10 to $100 \mu$.

3. Displacement production will be proportional to the distance which the energetic atom travels. Thus:

$$
\frac{d E}{d x}=\frac{d D}{d x}=C \text { or }-d E=C d x=d D
$$


4. The density of boron atoms within a $\mathrm{B}_{4} \mathrm{C}$ particle is constant.

If a $B^{10}(n, \alpha)$ reaction occurs within a $B_{4} C$ particle, the number of displacements which will be caused in the graphite will depend on the diameter of the particle and the position of the fissioning boron atom within the $\mathrm{B}_{4} \mathrm{C}$ particle.

An effectiveness term can be calculated to estimate the damage caused by boron atoms in a particle of assumed average size. This term will depend on the above two variables plus the path length of the reaction products outside the $\mathrm{B}_{4} \mathrm{C}$ particle.

The effectiveness can be considered as the product of three probability terms. The first term, $P_{1}$, is the probability of a $\mathrm{B}^{10}$ atom being within a spherical shell having a volume $\mathrm{V}_{Z}$ :

$$
P_{1}=\frac{V_{Z}}{V_{T}} \text {. }
$$

This term defines the probability that the reacting $B^{10}$ atom 1 ies within one mean free path of the surface of the $\mathrm{B}_{4} \mathrm{C}$ particle. However, the reaction products may not emerge unless they are emitted in a direction which will enable them to penetrate the surface of the particle. Since the products are emitted isotropically, another probability term can be defined as the solid angle of emergence divided by $4 \pi$.

$$
P_{2}=\frac{\theta}{4 \pi} \text {. }
$$

where $\theta=$ the solid angle subtended by the cone whose origin is the fissioning boron atom and whose surface length is the mean path length of the fragment atom. The $\mathrm{Li}^{7}$ and $\mathrm{He}^{4}$ atoms will emerge isotropically but can damage the graphite only if they emerge within the solid angle $\theta$. 
The third term, $\mathrm{P}_{3}$, is the mean fraction of the path length of a $\mathrm{Li}^{7}$ or $\mathrm{He}^{4}$ particle which 1 ies in the graphite:

$$
\mathrm{P}_{3}=\ell / \rho
$$

where $\ell$ is the distance traveled by the particle in the graphite and $\rho$ is the total path length of the particle.

This mean fractional length can be calculated by dividing the volume of the spherical cap, which is that part of the sphere of influence of the fissioning atom within the graphite, by its surface area, and yields the average radial distance across the segment.

Therefore, the effectiveness index is:

$$
A=P_{1} P_{2} P_{3}
$$

and the number of displacements caused in graphite by any $\mathrm{B}^{10}$ atom undergoing an $(n, \alpha)$ reaction is

$$
\mathrm{D}=\frac{\mathrm{A}}{\bar{\Sigma}_{\mathrm{D}}} \text {. }
$$

The relationship between $A$ and the $B_{4} \mathrm{C}$ particle size was determined by calculating A values for particle sizes ranging between 10 and $100 \mu$ in diameter.

The results of these calculations indicate that the function $A$ is 1.0 at $r=0$ and approaches an average value of 0.055 for particles with radii between 5 and $50 \mu$. This value of A was determined by integration of the function between these limits of $r$. 


\section{REFERENCES}

1. J. M. Davidson and L. O. Gates. Boronated Graphite Studies. Final Report of Irradiation Experiments Conducted in a Hanford Reactor, BNWL-96. June, 1965.

2. L. O. Gates and R. Neidner. Boronated Graphite Irradiation Studies - Summary Report of Thermal-Neutron-Shielded Experiments Conducted in the ETR, BNWL-161. October, 1965.

3. R. E. Dahl and H. H. Yoshikawa. "Neutron Exposure Correlations for Radiation Damage Studies," Nucl. Sci. and Engineering, vo1. 21, pp. 312-318. 1965.

4. C. E. Lowe11. Research Studies to Determine Phase Equilibrium Relations of Selected Metal Carbides at High Temperature, WADD-TDR-60-140. Westinghouse Electric Corporation.

5. J. M. Davidson, L. O. Gates, and R. E. Nightingale. RadiationDamage Effects in Boronated Graphite, BNWL-SA-104. June, 1965.

6. G. J. Dienes and G. H. Vineyard. Radiation Effects in Solids, Interscience Publishers, Inc., New York, 1957.

7. G. H. Kinchin and R. S. Pease. "The Displacement of Atoms in Solids by Radiation," Rpts. Prog. Phys., vol. 18, pp. 1-15. 1955 . 


\section{ONSITE DISTRIBUTION}

Copy Number

Pacific Northwest Laboratory

1

2

3

$4-13$

14

15

16

17

18

19

20

21

22

23

24

25

26

27

28

29

30

$31-35$

$36-37$

$38-42$

43

44
F. W. Albaugh

E. R. Astley

T. T. Claudson

R. E. Dah 1

G. M. Dalen

D. R. de Halas

J. M. Davidson

A. Depino

J. B. Goebel

J. W. Helm

R. S. Hope

J. L. Jackson

L. D. Johnson

W. C. Morgan

R. E. Nightingale

J. C. Stauffer

J. A. Ulseth

E. E. Voiland

R. E. Woodley

E. M. Woodruff

H. H. Yoshikawa

Technical Information Files

Technical Publications

Extra

Richland Operations Office

R. K. Sharp

Technical Information Library
OFFSITE DISTRIBUTION

\section{No. of Copies}

1

4

10
Argonne National Laboratory, Idaho Division Attn: R. Neidner

Atomic Energy Commission, Washington

Division of Reactor Development and Technology Attn: J.E. Fox (2)

J Morrisey

J. M. Simmons

Atomic Power Development Associates, Inc. Attn: W. E. McHugh 


\author{
OFFSITE DISTRIBUTION (Special) (Cont ' $d$ ) \\ No. of Copies \\ 2 \\ Atomics International \\ Attn: K. W. Foster \\ 2 \\ Chicago Operations Office \\ Attn: F. C. Mattmueller \\ 3 \\ General Atomic Division \\ Attn: G. B. Engle(2) \\ R. A. Meyer \\ 2 \\ Great Lakes Carbon Corporation \\ Research and Development Department \\ P. O. Box 637, Niagara Fa11s, N. Y. \\ Attn: L. H. Juel \\ 4 \\ Power Reactor Development Company \\ 911 First Street \\ Detroit, Michigan \\ Attn: R. W. Hartwell \\ 2 \\ Speer Carbon Company \\ Research and Development Laboratories \\ Packard $R$ \& 47 th St. \\ Niagara Fal1s, N. Y. \\ Attn: W. E. Parker \\ 2 \\ Union Carbide Corporation, Cleveland \\ Attn: J.T. Meers
}


trom 